RMD

Open

Rheumatic \&

Musculoskeletal

Diseases

To cite: Veale DJ, Fearon U.

What makes psoriatic and rheumatoid arthritis so different? RMD Open 2015;1: e000025. doi:10.1136/ rmdopen-2014-000025

- Prepublication history for this paper is available online. To view these files please visit the journal online (http://dx.doi.org/10.1136/ rmdopen-2014-000025).

Received 7 February 2015

Revised 31 March 2015

Accepted 5 April 2015

\title{
What makes psoriatic and rheumatoid arthritis so different?
}

\section{ABSTRACT}

In many ways, it may be easier to highlight what rheumatoid arthritis (RA) and psoriatic arthritis (PsA) have in common. They are both common conditions characterised by a spectrum of features or clinical manifestations in different organ systems that have led many to conclude that they are actually 'disease syndromes'. Furthermore, many of the organ systems that are affected in both conditions are the same: skin, joints, eyes, vasculature and even the immune system. Indeed, some clinicians fail to recognise these two common arthritides as distinct. And yet, while the manifestations may have a superficial similarity, there are significant differences at a number of levels including clinical, anatomical, microscopic and molecular levels. However, these differences may explain certain clinical manifestations of the two diseases, and more importantly, they may explain different responses to specific therapies and potentially different disease outcomes and prognoses. This may be especially relevant as new therapeutic targets are examined that may be specific for RA or PsA.

\section{CLINICAL AND ANATOMICAL FEATURES}

On the surface, the most striking similarity is that of arthritis: tender, soft tissue swelling of the joints, and in the majority of cases (psoriatic arthritis (PsA) 70\%; rheumatoid arthritis (RA) $80 \%$ ) the same joints are involved, symmetrical synovitis of the proximal interphalangeal and metacarpophalangeal joints of the hands. However, even though there are superficial similarities, several differences are evident on closer inspection. The first description of subtle differences in the clinical features of joint swelling came in 1973 when Professor Verna Wright in Leeds suggested that PsA displayed features consistent with spondyloarthopathy, distinct from RA. ${ }^{1}$ This was followed up with studies of hereditability of psoriasis in over 100 index cases, ${ }^{2}$ and accompanied by detailed radiographic examinations based on the distinct patterns of bony abnormality and joint erosion described previously by Avila et $a l^{3}{ }^{3}$ It was

\section{Key messages}

What is already known about this subject?

- The most consistent difference between PSA and $R A$ is the presence of autoantibodies in RA.

What does this study add?

- This report highlights clinical, pathogenic and molecular differences between PSA and RA.

How might this impact on clinical practice?

- These differences may explain differential responses to specific biological therapies.

noted that the characteristic bony lesion in PsA is a large erosion of the bony cortex, poorly demarcated, in a para-articular site compared with the often neatly demarcated articular margin of the RA erosion, but the PsA erosion also appeared to be closely associated with new bone formation. Recent developments in MRI and microcomputerised tomography have defined these changes more precisely in patients with PsA comparing them with RA erosions and osteoarthritis osteophytes. ${ }^{4}$ Interestingly, the advent of MRI has also enabled detailed studies of the site of inflammation in the small joints of the hands, leading to the concept of enthesitis alongside synovitis that explains some differences of clinical examination originally described on the surface of these joints. ${ }^{5}$ McGonagle has further expanded the concept of enthesitis examining the anatomical detail of the ligamentous insertions around the distal interphalangeal (DIP) joints to explain some of the clinical features in PsA. MRI also revealed the extent and distribution of synovial tissue inflammation within the joints ${ }^{6}$ although the synovium has been the subject of several studies focused on the pathogenesis of RA and PsA. The clinical and radiological changes strongly support a pattern of joint inflammation and damage in PsA, distinct from RA, that match findings in the seronegative spondyloarthropathies. The 
Table 1 Summary of key differences in PsA and RA

\begin{tabular}{|c|c|c|}
\hline & Psoriatic arthritis & Rheumatoid arthritis \\
\hline Clinical/anatomical & $\begin{array}{l}\text { DIP joint and axial arthritis } \\
\text { Often asymmetrical } \\
\text { Enthesitis common }\end{array}$ & $\begin{array}{l}\text { MCP and wrist joints } \\
\text { Predominantly symmetrical }\end{array}$ \\
\hline Genetic & $\begin{array}{l}\text { HLA Cw6 and B27 } \\
\text { IL23 receptor }\end{array}$ & - HLA DRB1 \\
\hline Pathogenesis & $\begin{array}{l}\text { - Absence of circulating autoantibodies } \\
\text { Distinct vascular pathology } \\
\text { - T-lymphocyte predominance } \\
\text { - Early expression of vascular growth factors }\end{array}$ & $\begin{array}{l}\text { Circulating autoantibodies RF/ACPA } \\
\text { T-lymphocyte and B-lymphocyte infiltrate } \\
\text { Late expression of vascular growth factors }\end{array}$ \\
\hline Response to therapy & $\begin{array}{l}\text { DMARDs, eg, methotrexate } \\
\text { TNF inhibitors } \\
\text { - Abatacept } \\
\text { - Ustekinumab } \\
\text { - Secukinumab }\end{array}$ & $\begin{array}{l}\text { DMARDs, eg, methotrexate } \\
\text { TNF inhibitors } \\
\text { Abatacept } \\
\text { Rituximab } \\
\text { Tocilizumab }\end{array}$ \\
\hline
\end{tabular}

ACPA, anticitrullinated protein antibodies; DIP, distal interphalangeal; DMARDs, disease modifying anti-rheumatic drugs; HLA, human leucocyte antigen; IL, interleukin; MCP, metacarpophalangeal; RF, rheumatoid factor; TNF, tumour necrosis factor.

association with erosive disease highlights the importance of early diagnosis and aggressive treatment to maximally maintain function (table 1 ).

Additional differences in the pattern of joint involvement were also described at an early stage. The original Moll and Wright classification of PsA proposed that DIP joints were frequently inflamed in PsA in direct contrast with RA. While they described up to $60 \%$ of patients with DIP joint disease alone, today the figure is reported to be $20 \%$ of cases. Another notable difference from $\mathrm{RA}$, is the involvement of the axial skeleton, including the sacroiliac joints and the lumbosacral spine, similar to but not identical to ankylosing spondylitis, this has led to PsA being included in the spectrum of spondyloarthopathies. ${ }^{1}$ These features, of course, support the concept of enthesitis in this family of diseases, and is further strengthened by the association with the major histocompatibility complex (MHC) class I antigen human leucocyte antigen (HLA) B27, as opposed to the MHC class II shared epitope, HLA DRB1, associated with RA, and therefore clearly defines a difference in genetic susceptibility and pathogenesis of PsA and RA. ${ }^{7}$ Recently, several genes associated with ankylosing spondylitis and inflammatory bowel disease have been identified in a significant proportion of patients with PsA including the interleukin (IL) 23 receptor, CARD9 and ERAP1. ${ }^{8}$ Interestingly, a recent study in an animal model of spondyloarthropathy by Sherlock et $a l^{9}{ }^{9}$ demonstrated a unique population of entheseal resident $\mathrm{T}$ cells expressing the IL23 receptor. In vivo expression of IL23 led to production of IL17 and IL22 from these cells and the development of enthesitis characterised by entheseal new bone formation in the absence of synovitis.

\section{PATHOGENESIS AND PATHOPHYSIOLOGY}

Early studies of the synovial tissue at a microscopic level used a Parker-Pearson needle to obtain biopsies 'blindly' from the suprapatellar region under local anaesthetic.
Initial studies in RA defined the microscopic features of synovitis, such as villous formation, increased mononuclear cell infiltrate, and increased vascularisation. The first studies to perform detailed microscopic examinations in PsA revealed changes that were quite different. The most significant histological changes were vascular, characterised by endothelial swelling and vessel wall thickening. ${ }^{10}$ Subsequent studies compared directly synovial tissue biopsies from patients with PsA and RA that demonstrated a less cellular infiltrate, more vascular tissue in PsA than RA, in addition, the characteristic hyperplasia of the lining layer of cells observed in RA was less marked in PsA synovium. ${ }^{11}$ The increased vascular staining using factor VIII-related von Willebrand Factor antibodies by immunohistochemistry and immunofluoresence (figure 1) was assumed to represent increased numbers of new blood vessels in PsA synovium. Consistent with this finding, several studies demonstrated increased expression of angiogenic growth factors, such as vascular endothelial growth factor (VEGF), angiopoietin 2 (Ang2), and basic fibroblast growth factor (BFGF) in PsA synovium compared to RA. ${ }^{12}$ Furthermore, in PsA, increased expression of vascular adhesion molecule 1 (VCAM-1) and
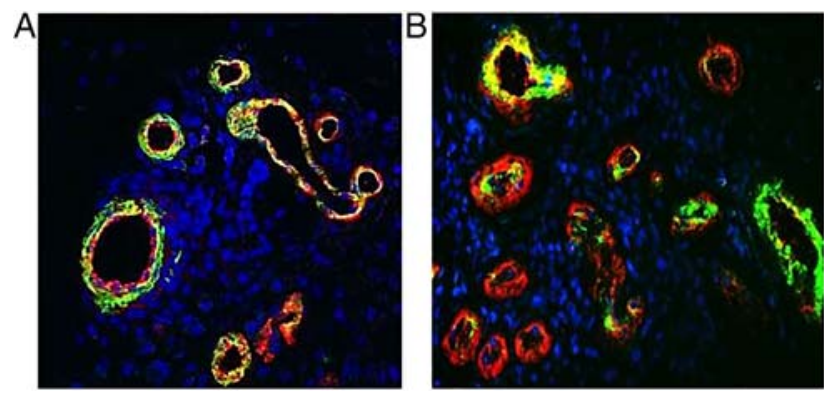

Figure 1 Immunofluorescent staining of blood vessels in (A). Rheumatoid arthritis compared with $(B)$. Psoriatic arthritis (PsA), illustrating increased immature blood vessels in PsA synovium. 
intercellular adhesion molecule 1 (ICAM-1), along with reduced expression of E-selectin are described. It has been suggested that fewer $\mathrm{T}$ and $\mathrm{B}$ cells are found in PsA compared with RA, although, as aforementioned, specific subsets of $\mathrm{T}$ cells, such as Th17 cells, may be over-represented and responsible for driving inflammation. ${ }^{14}$ The role of $\mathrm{T}$ cells in PsA synovium has been highlighted by the beneficial effects on T-cell therapies, such as ciclosporin and abatacept in the treatment of synovitis in PsA. ${ }^{15}{ }^{16}$ B-cell aggregates have been noted in PsA and RA synovial biopsies, occasionally forming lymphoid follicles, this raised the question 'What B cells are doing in the synovium of patients with PsA? ${ }^{11}$ PsA has not been associated with circulating antibodies, in contrast to those in RA. Indeed, there has been considerable controversy around the diagnosis of PsA, and the presence or absence of rheumatoid factor (RF) in the circulation. Some argue that a positive RF does not outrule the diagnosis of PsA, while others suggest a positive RF should rule out the diagnosis of PsA. The publication of the landmark CASPAR study and related criteria does conclude that RF has a significantly high discriminant value, such that a negative result forms one of five possible criteria, three of which are required to make a diagnosis of PsA. ${ }^{17}$ It has been subsequently confirmed that PsA is not usually associated with circulating autoantibodies, including anticitrullinated protein antibodies (ACPA) ${ }^{18}$ It may be hypothesised that the B cells in the synovial tissue are fulfilling a T-cell activating or cooperative role; however, this remains to be proven, and it is not yet known if the presence of B cells in PsA synovium predict response to anti-B-cell targeted therapies, such Rituximab; however, reports of case studies to date have not shown efficacy in PsA. ${ }^{19}$

Despite the site-specific differences noted on MRI as described above, direct visualisation using arthroscopy initially suggested significant similarity in the joints of patients with RA and PsA. Arthroscopy using small $(<2.9 \mathrm{~mm})$ needle telescopes introduced under local anaesthesia was performed by a small number of rheumatologists in many countries worldwide in the 1990s. ${ }^{20}$ Prior to that time, few rheumatologists undertook arthroscopic examinations. At first, the synovium appeared similar in both conditions-erythematous, hypervascularised with villi 'frond-like' proliferations or granular swelling into the joint cavity. It was assumed that all inflammation was the same. It was not until the latter part of that decade that observations in relation to the vascularisation of the synovial tissue were described in detail, that again suggested significant differences between PsA and RA. ${ }^{21}$ In this study, Reece et al described a significant difference in the pattern of new blood vessels in PsA and RA, indicating that 'not all inflammation is the same'! This distinct pattern of new blood vessel formation in PsA and the seronegative spondyloarthropathies has been confirmed in subsequent studies. ${ }^{22}$ In the former, the vessels form a hypervascularised network of elongated, tortuous vessels suggesting
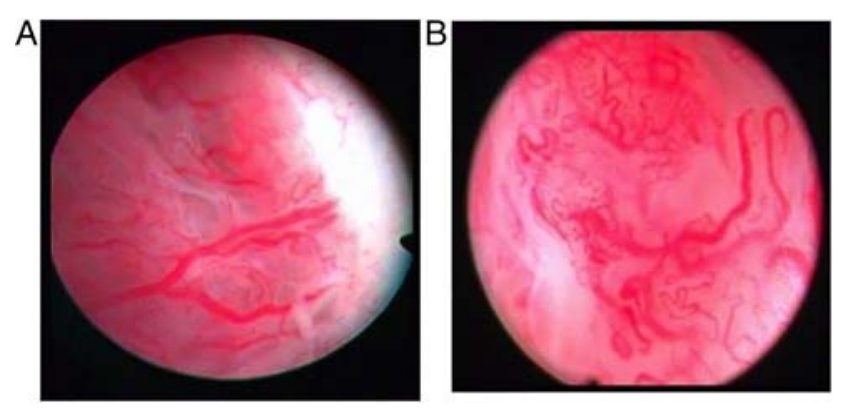

Figure 2 Macroscopic appearance of synovial membrane vascularity in (A). Rheumatoid arthritis (RA) compared with (B). Psoriatic arthritis (PsA), illustrating straight, branching blood vessels in RA compared with a tortuous vascular pattern in PsA synovium.

the proliferation of existing vessels by extension only, while in RA, the vessels show regular branching (figure 2) similar to the neovascularisation seen in diabetes. Furthermore, at a microscopic level, the increased vessels previously noted on immunohistology in PsA synovium may be due to the elongation and increased tortuosity of existing vessels, rather than an increase in the actual number of new vessels. These observations are supported by the findings on a molecular level of different vascular growth factor expression patterns, especially VEGF and Ang2, found at high levels in synovial tissue of the early stage of PsA. This compares with moderate levels of VEGF and Ang1 in the early phase of $\mathrm{RA}$, increasing in the later stages of the disease. ${ }^{13} 23$ Additionally, the blood vessel changes in the joints in PsA are very similar to those noted in the dermis of the skin in psoriasis. ${ }^{24}$ In RA, a very different systemic vascular response may also be observed, that of a smallmedium vessel vasculitis associated with a leucocytoclastic perivascular infiltrate. While the systemic response in both conditions suggests an active inflammatory immune reaction, evidence for this is more often found in RA, presumed to match the autoimmune nature of RA characterised by production of autoantibodies as outlined above. In PsA, the systemic immune response may also be apparent, however, it is often less marked than in RA. In many clinical studies and trials, it is noted that the mean rise in circulating markers of inflammation, such as erythrocyte sedimentation rate, $\mathrm{C}$ reactive protein (CRP), or serum amyloid A, is significantly lower in the PsA population in contrast with patients with RA. ${ }^{25}$ This observation, along with the absence of specific autoantibodies has led to the hypothesis that PsA is an autoinflammatory disease lacking evidence of specific autoimmune reactivity. Similarities in this respect have been drawn between PsA and other systemic conditions characterised by disturbance of the inflammasome. ${ }^{26}$

\section{THERAPEUTIC RESPONSES}

First-line disease modifying anti-rheumatic drugs (DMARDs), such as methotrexate (MTX) and 
leflunomide are effective in the management of both RA and PsA although there is a wealth of clinical trial evidence for the use of MTX in RA, whereas in PsA, the evidence is sparse.

The introduction of tumour necrosis factor inhibitors (TNFi) led to a major shift in the treatment of RA and PsA irrespective of the diagnosis. ${ }^{27}$ Indeed, this comparative study in patients with PsA and RA matched for disease activity, suggested that the remission rate was higher in PsA $(60 \%)$ than in RA $(44 \%)$. The benefit of TNFi in PsA, includes an effect on spinal symptoms present in up to $25 \%$, and in dactylitis and nail disease manifest in $20 \%$ of patients, while synthetic DMARDs show little efficacy. ${ }^{28}$ There are now five TNFi agents approved for use in patients with PsA, all showing equivalent efficacy in the treatment of joint disease, while recent data suggests relevant clinical effects as early as 24 weeks. $^{29}$ The major difference between synthetic DMARDs and TNFi is the effect on inhibition of bone damage, suggesting that use of TNFi early in the disease course is potentially of greater benefit to patients. PsA is not a benign disease, as progression and joint damage are observed over time. A cohort of patients with PsA attending an early arthritis clinic, and receiving treatment with synthetic DMARDs, demonstrated significant bone erosions over a 2-year period. ${ }^{30}$

Several new biological agents targeting novel molecules implicated in the inflammatory pathway have now been developed and are available. The interesting observation thus far is that some of these treatments are highly effective in RA but have shown little benefit in the treatment of patients with PsA. In particular, monoclonal antibodies (Mab) against CD20 molecule expressed on B cells and the IL6 receptor, appear to be effective in patients with RA but not in patients with PsA. This may not be surprising, as noted above, there is an absence of circulating autoantibodies in PsA. Moreover, the acute-phase marker CRP, which may reflect IL6 production, is often lower in patients with PsA compared with patients with RA; however, there is no evidence that the IL6R Mab is effective in patients with PsA who do have a high CRP. One biological agent, a fusion protein against CTLA-4 (abatacept) results in down modulation of T-cell activation, however, does show similar activity in both patients with PsA and RA. Recent advances in our understanding of the pathophysiology of PsA, as outlined above, has led to a focus on the IL17, IL12/IL23 pathway as a potential therapeutic target. Several Mab targeting this key regulatory pathway have now been developed and studied in the setting of PsA and psoriasis. A fully human anti-IL12/ IL23 Mab, ustekinumab, has been studied in two large, phase III randomised clinical trials to show safety and efficacy in the treatment of PsA. ${ }^{31} 32$ The ustekinumab studies included over 600 patients with active PsA and showed significant responses compared with placebo over a 52-week study period, and may therefore offer a specific, alternative, biological, therapeutic mechanism for the treatment of PsA. Ustekinumab studies in RA have been completed but not yet published, another anti-IL17 Mab, (AIN457) secukinumab, was reported to be efficacious in psoriasis, uveitis and rheumatoid arthritis, and the effect in RA has been confirmed, with a stable adverse event profile, in a double-blind, randomised, placebo-controlled study of over 200 patients with RA. $^{33} 34$ Secukinumab, a fully human anti-IL17A Mab has also been shown to have some efficacy in a small proof-of-concept study in the treatment of patients with PsA. ${ }^{35}$ This study included 42 patients over a 24-week period, and it failed to meet the primary end point; however, significant improvements in secondary measures were observed. Finally, two anti-IL17 receptor antibodies, brodalimumab and ixekizumab, were shown in short phase II studies to be significantly beneficial in plaque psoriasis. ${ }^{35} 36$ Brodalimumab, which is an anti-IL17 receptor Mab has now been shown to be efficacious in PsA in a 52-week randomised, double-blind, placebo-controlled study. ${ }^{37}$

In conclusion, this review outlines the similarities and the differences in PsA and RA. In many respects, the similarities may be superficial and restricted to the clinical or 'macro' view of the diseases. By contrast, the differences may be more than skin deep! Significant differences have been observed at the clinical, immunological, cellular and molecular levels. Specifically, the most defined differences focus around the absence of autoantibodies, RF and ACPA, the vascular morphology and angiogenic growth factor expression in the synovial tissue, and the pattern of periarticular inflammation, bone erosion and formation at the entheseal complex of peripheral and spinal joints. Finally, while some synthetic and biological DMARDs appear to be effective in both patients with PsA and RA, again, specific differences in response to new targeted therapies are being observed which may be explained by specific differences in the molecular pathogenesis of PsA compared with RA.

Funding DJV and UF received funding from the IMI JU 'BeTheCure' programme (contract no 115142-2), The Health Research Board of Ireland and the Higher Education Authority of Ireland-PRTLI cycles 4 and 5 funding.

Competing interests Both authors have received fees for speaking, consulting and/or research grants from AbbVie, Actelion, BMS, Boehringer, Janssen, MSD, Medimmune, Pfizer, Roche and UCB.

Provenance and peer review Commissioned; externally peer reviewed.

Data sharing statement No additional data are available.

Open Access This is an Open Access article distributed in accordance with the Creative Commons Attribution Non Commercial (CC BY-NC 4.0) license, which permits others to distribute, remix, adapt, build upon this work noncommercially, and license their derivative works on different terms, provided the original work is properly cited and the use is non-commercial. See: http:// creativecommons.org/licenses/by-nc/4.0/

\section{REFERENCES}

1. Moll JM, Wright V. Psoriatic arthritis. Semin Arthritis Rheum 1973;3:55-78.

2. Moll JM, Wright V. Familial occurrence of psoriatic arthritis. Ann Rheum Dis 1973;32:181-201. 
3. Avila R, Pugh DG, Slocumb $\mathrm{CH}$, et al. Psoriatic arthritis: a roentgenologic study. Radiology 1960;75:691-702.

4. Finzel S, Englbrecht M, Engelke K, et al. A comparative study of periarticular bone lesions in rheumatoid arthritis and psoriatic arthritis. Ann Rheum Dis 2011:70:122-7.

5. McGonagle D, Conaghan PG, Emery P. Psoriatic arthritis: a unified concept twenty years on. Arthritis Rheum 1999;42:1080-6.

6. Kennedy A, Ng CT, Chang TC, et al. Tumor necrosis factor blocking therapy alters joint inflammation and hypoxia. Arthritis Rheum 2011;63:923-32.

7. Gladman DD, Farewell VT, Rahman P, et al. HLA-DRB ${ }^{*} 04$ alleles in psoriatic arthritis: comparison with rheumatoid arthritis and healthy controls. Hum Immunol 2001;62:1239-44.

8. Dougados M, Baeten D. Spondyloarthritis. Lancet 2011;377:2127-37.

9. Sherlock JP, Joyce-Shaikh B, Turner SP, et al. IL-23 induces spondyloarthropathy by acting on ROR-gt+CD3+CD4-CD8entheseal resident T cells. Nat Med 2012;18:1069-76.

10. Espinoza LR, Vasey FB, Espinoza CG, et al. Vascular changes in psoriatic synovium. A light and electron microscopic study. Arthritis Rheum 1982;25:677-84.

11. Veale DJ, Yanni G, Rogers S, et al. Reduced synovial membrane macrophage numbers, ELAM-1 expression, and lining layer hyperplasia in psoriatic arthritis as compared with rheumatoid arthritis. Arthritis Rheum 1993;36:893-900.

12. Fraser A, Fearon U, Reece R, et al. Matrix metalloproteinase 9, apoptosis, and vascular morphology in early arthritis. Arthritis Rheum 2001;44:2024-8.

13. Fearon U, Griosios K, Fraser A, et al. Angiopoietins, growth factors, and vascular morphology in early arthritis. $J$ Rheumatol 2003;30:260-8.

14. Yeremenko N, Baeten D. IL-17 in spondyloarthritis: is the T-party over? Arthritis Res Ther 2011;13:115.

15. Fraser AD, van Kuijk AW, Westhovens $\mathrm{R}$, et al. A randomised, double blind, placebo controlled, multicentre trial of combination therapy with methotrexate plus ciclosporin in patients with active psoriatic arthritis. Ann Rheum Dis 2005;64:859-64.

16. Mease P, Genovese MC, Gladstein G, et al. Abatacept in the treatment of patients with psoriatic arthritis: results of a six-month, multicenter, randomized, double-blind, placebo-controlled, phase trial. Arthritis Rheum 2011;63:939-48.

17. Taylor W, Gladman $D$, Helliwell $P$, et al. Classification criteria for psoriatic arthritis: development of new criteria from a large international study. Arthritis Rheum 2006;54:2665-73.

18. Sanmartí R, Graell E, Perez ML, et al. Diagnostic and prognostic value of antibodies against chimeric fibrin/filaggrin citrullinated synthetic peptides in rheumatoid arthritis. Arthritis Res Ther 2009;11:R135.

19. Huynh D, Kavanaugh A. Psoriatic arthritis: current therapy and future approaches. Rheumatology 2015;54:20-8.

20. Kane D, Veale DJ, FitzGerald O, et al. Survey of arthroscopy performed by rheumatologists. Rheumatology 2002;41:210-15.

21. Reece RJ, Canete JD, Parsons WJ, et al. Distinct vascular patterns of early synovitis in psoriatic, reactive, and rheumatoid arthritis. Arthritis Rheum 1999;42:1481-4.
22. Fiocco U, Cozzi L, Chieco-Bianchi F, et al. Vascular changes in psoriatic knee joint synovitis. J Rheumatol 2001;28:2480-6.

23. Salvador G, Sanmartí R, Gil-Torregrosa B, et al. Synovial vascular patterns and angiogenic factors expression in synovial tissue and serum of patients with rheumatoid arthritis. Rheumatology 2006;45:966-71.

24. Veale DJ, Ritchlin C, FitzGerald O. Immunopathology of psoriasis and psoriatic arthritis. Ann Rheum Dis 2005;64(Suppl 2):iiP9.

25. Cunnane G, Grehan S, Geoghegan S, et al. Serum amyloid A in the assessment of early inflammatory arthritis. J Rheumatol 2000;27:58-63.

26. McGonagle D, McDermott MF. A proposed classification of the immunological diseases. PLoS Med 2006;3:e297.

27. Saber TP, $\mathrm{Ng} \mathrm{C}$, Renard G, et al. Remission in psoriatic arthritis: is it possible and how can it be predicted? Arthritis Res Ther 2010;12:R94.

28. Glintborg B, Østergaard M, Dreyer L, et al. Treatment response, drug survival, and predictors thereof in 764 patients with psoriatic arthritis treated with anti-tumor necrosis factor $\alpha$ therapy: results from the nationwide Danish DANBIO registry. Arthritis Rheum 2011;63:382-90.

29. Mease PJ, Fleischmann R, Deodhar AA, et al. Effect of certolizumab pegol on signs and symptoms in patients with psoriatic arthritis: 24-week results of a Phase 3 double-blind randomised placebocontrolled study (RAPID-PsA). Ann Rheum Dis 2014;73:48-55.

30. Kane D, Stafford L, Bresnihan B, et al. A prospective, clinical and radiological study of early psoriatic arthritis: an early synovitis clinic experience. Rheumatology 2003;42:1460-8.

31. McInnes IB, Kavanaugh A, Gottlieb AB, et al. Efficacy and safety of ustekinumab in patients with active psoriatic arthritis: 1 year results of the phase 3 , multicentre, double-blind, placebo-controlled PSUMMIT 1 trial. Lancet 2013;382:780-9.

32. Ritchlin C, Rahman P, Kavanaugh A, et al. Efficacy and safety of the anti-IL-12/23 p40 monoclonal antibody, ustekinumab, in patients with active psoriatic arthritis despite conventional non-biological and biological anti-tumour necrosis factor therapy: 6-month and 1-year results of the phase 3 , multicentre, double-blind, placebo controlled, randomised PSUMMIT 2 trial. Ann Rheum Dis 2014;73:990-9.

33. Hueber W, Patel DD, Dryja T, et al. Effects of AIN457, a fully human antibody to interleukin-17A, on psoriasis, rheumatoid arthritis, and uveitis. Sci Transl Med 2010;2:52ra72.

34. Genovese MC, Durez P, Richards HB. One-year efficacy and safety results of secukinumab in patients with rheumatoid arthritis: phase II, dose-finding, double-blind, randomized, placebo-controlled study. $J$ Rheumatol 2014;41:414-21.

35. McInnes IB, Sieper J, Braun J, et al. Efficacy and safety of secukinumab, a fully human anti-interleukin-17A monoclonal antibody, in patients with moderate-to-severe psoriatic arthritis: a 24-week, randomised, double-blind, placebo-controlled, phase II proof-of-concept trial. Ann Rheum Dis 2013;73:349-56.

36. Papp KA, Leonardi C, Menter A, et al. Brodalumab, an anti-interleukin-17-receptor antibody for psoriasis. $N$ Engl $J$ Med 2012;366:1181-9.

37. Mease PJ, Genovese MC, Greenwald MW, et al. Brodalumab, an anti-IL17RA monoclonal antibody, in psoriatic arthritis. N Engl J Med 2014;370:2295-306. 